University of Wollongong

Research Online

Faculty of Science - Papers (Archive)

Faculty of Science, Medicine and Health

$1-1-2012$

\title{
Oxidation of acid-volatile sulfide in surface sediments increases the release and toxicity of copper to the benthic amphipod Melita plumulosa
}

\author{
Stuart L. Simpson \\ CSIRO \\ Daniel Ward \\ University of Wollongong, djw64@uow.edu.au \\ David Strom \\ University of Wollongong, ds999@uow.edu.au \\ Dianne F. Jolley \\ University of Wollongong, djolley@uow.edu.au
}

Follow this and additional works at: https://ro.uow.edu.au/scipapers

Part of the Life Sciences Commons, Physical Sciences and Mathematics Commons, and the Social and Behavioral Sciences Commons

\section{Recommended Citation}

Simpson, Stuart L.; Ward, Daniel; Strom, David; and Jolley, Dianne F.: Oxidation of acid-volatile sulfide in surface sediments increases the release and toxicity of copper to the benthic amphipod Melita plumulosa 2012, 953-961.

https://ro.uow.edu.au/scipapers/4332

Research Online is the open access institutional repository for the University of Wollongong. For further information contact the UOW Library: research-pubs@uow.edu.au 


\title{
Oxidation of acid-volatile sulfide in surface sediments increases the release and toxicity of copper to the benthic amphipod Melita plumulosa
}

\begin{abstract}
Acid-volatile sulfides (AVS) are an important metal-binding phase in sediments. For sediments that contain an excess of AVS over simultaneously extracted metal (SEM) concentrations, acute or chronic effects should not result from the metals $\mathrm{Cd}, \mathrm{Cu}, \mathrm{Ni}, \mathrm{Pb}$ and $\mathrm{Zn}$. While AVS phases may exist in surface sediments, the exposure to dissolved oxygen may oxidize the AVS and release metals to more bioavailable forms. We investigated the role of oxidation of AVS, and specifically copper sulfide phases, in surface sediments, in the toxicity to juveniles of the epibenthic amphipod, Melita plumulosa. Sediments containing known amounts of copper sulfide were prepared either in situ by reacting dissolved copper with AVS that had formed in field sediments or created in sediments within the laboratory, or by addition of synthesised CuS to sediments. Regardless of the form of the copper sulfide, considerable oxidation of AVS occurred during the 10-d tests. Sediments that had a molar excess of AVS compared to SEM at the start of the tests, did not always have an excess at the end of the tests. Consistent with the AVS-SEM model, no toxicity was observed for sediments with an excess of AVS throughout the tests. However, the study highlights the need to carefully consider the changes in AVS concentrations during tests, and that measurements of AVS and SEM concentrations should carefully target the materials to which the organisms are being exposed throughout tests, which in the case of juvenile M. plumulosa is the top few $\mathrm{mm}$ of the sediments.
\end{abstract}

\section{Keywords}

surface, sediments, increases, oxidation, release, acid, toxicity, copper, benthic, amphipod, melita, plumulosa, volatile, sulfide

\section{Disciplines}

Life Sciences | Physical Sciences and Mathematics | Social and Behavioral Sciences

\section{Publication Details}

Simpson, S. L., Ward, D., Strom, D., Jolley, D. F. (2012). Oxidation of acid-volatile sulfide in surface sediments increases the release and toxicity of copper to the benthic amphipod Melita plumulosa. Chemosphere, 88 (8), 953-961. 
10 Oxidation of acid-volatile sulfide in surface sediments increases the release and 11 toxicity of copper to the benthic amphipod Melita plumulosa

13 Stuart L. Simpson ${ }^{1 *}$, Daniel Ward ${ }^{1,2}$, David Strom ${ }^{1,2}$, Dianne F. Jolley ${ }^{2}$

$14{ }^{1}$ Centre for Environmental Contaminants Research, CSIRO Land and Water, Lucas Heights, NSW 2234, Australia.

$15{ }^{2}$ School of Chemistry, University of Wollongong, NSW 2522, Australia

16 


\section{Abstract}

23 Acid-volatile sulfides (AVS) are an important metal-binding phase in sediments. For sediments that contain an

24 excess of AVS over simultaneously extracted metal (SEM) concentrations, acute or chronic effects should not

25 result from the metals $\mathrm{Cd}, \mathrm{Cu}, \mathrm{Ni}, \mathrm{Pb}$ and $\mathrm{Zn}$. While AVS phases may exist in surface sediments, the exposure to

26 dissolved oxygen may oxidise the AVS and release metals to more bioavailable forms. We investigated the role of

27 oxidation of AVS, and specifically copper sulfide phases, in surface sediments, in the toxicity to juveniles of the

28 epibenthic amphipod, Melita plumulosa. Sediments containing known amounts of copper sulfide were prepared

29 either in situ by reacting dissolved copper with AVS that had formed in field sediments or created in sediments

30 within the laboratory, or by addition of synthesised $\mathrm{CuS}$ to sediments. Regardless of the form of the copper sulfide,

31 considerable oxidation of AVS occurred during the 10-day tests. Sediments that had a molar excess of AVS

32 compared to SEM at the start of the tests, did not always have an excess at the end of the tests. Consistent with the

33 AVS-SEM model, no toxicity was observed for sediments with an excess of AVS throughout the tests. However,

34 the study highlights the need to carefully consider the changes in AVS concentrations during tests, and that

35 measurements of AVS and SEM concentrations should carefully target the materials to which the organisms are

36 being exposed throughout tests, which in the case of juvenile M. plumulosa is the top few mm of the sediments.

39 Keywords: Acid-volatile sulfide, oxidation, copper, toxicity, amphipod, sediment 


\section{Introduction}

It is widely recognised that for sediments containing a molar excess of acid-volatile sulfide (AVS) over

44 simultaneously-extracted metals ( $\left.\mathrm{SEM}=\sum \mathrm{Ag}, \mathrm{Cd}, \mathrm{Cu}, \mathrm{Ni}, \mathrm{Pb}, \mathrm{Zn}\right)$ the porewater concentrations of these metals will 45 be negligible and acute or chronic effects should not result from these metals (Ankley et al., 1993; Berry et al., 46 1996; USEPA, 2005; Simpson and Spadaro, 2011). The metal concentrations in excess of the binding capacity 47 attributed to AVS may be bound by other solid phases, including particulate organic carbon (POC) and iron and 48 manganese oxyhydroxide phases, or partition to the pore waters (Di Toro et al., 2005; Simpson and Batley, 2007). 49 Sediment quality guidelines (SQGs) that vary in proportion with AVS, POC and silt contents have been shown to offer a significant improvement on single value SQGs (Di Toro et al., 2005; Strom et al., 2011).

The redox conditions in sediments are usually stratified and zones are frequently referred to as oxic, suboxic, and anoxic (Jorgensen and Revsbech, 1985; Kristensen, 2000). In the present study, we refer to oxic sediments as surface sediments penetrated by dissolved oxygen, sub-oxic sediments as those contain mixtures of dissolved $\mathrm{Mn}$ (II) and Fe(II) in equilibrium with iron(III) and manganese(IV) oxyhydroxide phases but containing negligible dissolved oxygen or sulfide, and anoxic sediments as those in which dissolved sulfide and AVS are dominant. At the sediment-water interface of surface sediments and at burrow walls, dissolved oxygen generally only penetrates a few millimeters (Jørgensen and Revsbech, 1985; Kristensen, 2000; Gallon et al., 2008). While AVS phases may persist in surface sediments, having been formed under anoxic conditions or brought to the surface through bioturbation, the ongoing exposure to dissolved oxygen may result in oxidation of AVS and transfer of metals to more bioavailable forms). When exposed to dissolved oxygen, copper sulfide phases are slow to oxidise compared to iron and manganese sulfide phases (Simpson et al., 1998; Caetano et al., 2003). Copper that is released during the oxidation of copper sulfide phases is expected to become rapidly adsorbed to particulate organic carbon or iron and manganese oxyhydroxide phases (Chapman, et al., 1998; Simpson and Batley, 2003;

64 Eggleton and Thomas, 2004). Through the combination of the slow metal-sulfide oxidation processes, adsorption to sediment particles and dilution in surrounding water, dissolved metal concentrations in surface pore water and overlying water are commonly in the low $\mu \mathrm{g} \mathrm{L}^{-1}$ range and are generally not an environmental concern (Eggleton and Thomas, 2004; Simpson and Batley, 2007).

Most organisms live within oxic surface sediments or in oxygenated microenvironments created within suboxic and anoxic sediments (e.g. by irrigation of burrows with oxygen-containing waters). In these environments the binding of metals by AVS may vary considerably with time (Foster, 1996, Motelica-Heiono et al., 2003; Naylor et al., 2006; Gallon et al., 2008). Benthic invertebrates may also ingest significant quantities of sediment during their foraging for food, and dietary exposure to metals may elicit toxicity effects to some species (Simpson, 2005; Goulet et al., 2007; Wang et al., 2007; Mann et al., 2009; Casado-Martinez et al., 2010). The oxidation of AVS in surface sediments has the potential to increase the bioavailability of both dissolved and particulate metals (Peterson et a., 1996; Eriksson-Wiklund and Sundelin, 2002; De Lange et al., 2008).

In this study, we investigated the role of oxidation of AVS, and specifically copper sulfide phases, in surface 
the dissolved phase and through ingestion of sediment particles contribute to toxic effects for this epibenthic deposit-feeding amphipod (Simpson and King, 2005; King et al., 2006; Spadaro et al., 2008; Mann et al., 2009; Strom et al., 2011). This study aimed to demonstrate that AVS reduces the toxicity of copper, and to assess the degree of oxidation of copper sulfide phases in surface sediments, and provide further insight into the role of dietary exposure in any observed toxicity.

\section{Experimental procedures}

\subsection{General analytical}

New plasticware was used for all chemical analyses. All chemicals were analytical reagent grade or equivalent analytical purity. Deoxygenated waters were prepared by bubbling solutions with high purity oxygenfree nitrogen gas for $>8 \mathrm{~h}$ to give dissolved oxygen concentrations $<0.1 \mathrm{mg} \mathrm{L}^{-1}$. Measurements of $\mathrm{pH}$, salinity, temperature and dissolved oxygen were made in accordance with the instrument manufacturers' instructions. Methods for measurements of $\mathrm{pH}$, particle size fractions (wet sieving and gravimetry), total organic carbon (TOC, high temperature analyser), and particulate metals (2:1 concentrated $\mathrm{HCl}: \mathrm{HNO}_{3}$, heated) were made as described previously (Simpson et al., 2000a; Simpson et al., 2007). Sediment pore water was extracted by centrifugation (5 min, $1700 \mathrm{~g}, 18$ to $22^{\circ} \mathrm{C}$ ) under a nitrogen atmosphere (Simpson et al., 2000a). Pore water and overlying water samples were rapidly filtered through acid-washed $0.45 \mu \mathrm{m}$ membrane filters (Minisart, Sartorius) immediately following collection and acidified to $2 \% \mathrm{HNO}_{3}(\mathrm{v} / \mathrm{v})$ with concentrated $\mathrm{HNO}_{3}$ (Tracepur, Merck). Acid-volatile sulfide and simultaneously extracted metals (SEM) were analysed according to Simpson (2001). Any samples for AVS analyses were stored frozen in container with no head space or a nitrogen atmosphere immediately after sampling, and all subsequent handling, including thawing, was undertaken in a nitrogen gas atmosphere (De Lange et al., 2008). Dissolved metal concentrations in water samples and digested sediments were determined by inductively coupled plasma-atomic emission spectrometry (ICP-AES, Spectroflame EOP, Spectro Analytical Instruments) calibrated with matrix-matched standards. Analyses of filter and digest blanks, replicates for $20 \%$ of samples, analyte sample-spikes and the certified reference material (PACS-2, National Research Council Canada) were made as part of the quality assurance and recoveries were within $85-110 \%$ of expected values. The limits of reporting for the various methods were less than one tenth of the lowest reported values. All sediment related concentrations are reported on a dry mass basis.

\subsection{Test media}

Clean seawater was collected from Port Hacking, Sydney, Australia, membrane filtered $(0.45 \mu \mathrm{m})$, and acclimated to room temperature of $\left(21 \pm 1^{\circ} \mathrm{C}\right)$. Where necessary, the salinity of the filtered seawater was adjusted to the test salinity of $30 \mathrm{PSU}$ using deionised water $\left(18 \mathrm{M} \Omega \mathrm{cm}^{-1}\right.$ or $0.055 \mu \mathrm{S} \mathrm{cm}^{-1}$, Milli-Q ${ }^{\circledR}$ Millipore). Silty sediments with low to moderate metal contamination and negligible concentrations of organic contaminants were collected from the mangrove forest lined Bonnet Bay, Woronora River, Australia, as described previously (Simpson et al., 2004). At this site, sediments containing both low AVS ( $<0.5$ to $\left.2 \mu \mathrm{mol} \mathrm{g}^{-1}\right)$ and high AVS (28 to $\left.32 \mu \mathrm{mol} \mathrm{g}{ }^{-1}\right)$ were collected. The high AVS material was typically located in layer at $2-4 \mathrm{~cm}$ depth in sediments 
within the mangroves, whereas the low AVS material was the dominant material on the bay side of the mangroves. Both the low and high AVS sediments were hydrous (70\% water), silty (95\% of particles $<63 \mu \mathrm{m}$ ), contained $4 \%$ TOC and had porewater $\mathrm{pH}$ values of 7.1 to 7.8. Particulate metal concentrations were similar for both the low and high AVS materials: 2.1-2.6\% Fe, and $\mathrm{Cd}, \mathrm{Cu}, \mathrm{Mn}, \mathrm{Ni}, \mathrm{Pb}$ and $\mathrm{Zn}$ of 1-3, 30-50, 50-80, 3-10, 40-70, and 150$250 \mathrm{mg} \mathrm{kg}^{-1}$, respectively (Simpson et al., 2004; Strom et al., 2011).

\subsection{Preparation of sediments containing copper sulfide.} nitrogen gas-filled glove box at room temperature following the procedures described in Simpson et al. (2004). The sediments were thoroughly homogenised by mixing with a plastic spoon and then on a bottle roller for $2 \mathrm{~h}$ at least twice per week. At higher copper-spike concentrations, the $\mathrm{pH}$ decreased, so the $\mathrm{pH}$ of the sediments was adjusted to $\mathrm{pH} 7.5$ with $1 \mathrm{M} \mathrm{NaOH}$ one day after copper-spiking and maintained at this $\mathrm{pH}$ by small additions of $\mathrm{NaOH}$ throughout the one-month equilibration period. Changes in $\mathrm{pH}$, redox potential, and dissolved metals in the pore water were monitored during this period.

Three methods were used to create substrates containing copper sulfide. The high-AVS sediment was diluted with low-AVS sediment and equilibrated for 5 days to create sediments with AVS concentrations of 11, 18 and $30 \mu \mathrm{mol} \mathrm{g} \mathrm{g}^{-1}$. Each of these three sediments was spiking with the required amounts of copper sulfate dissolved in deoxygenated water to achieve a series of 5 to 6 concentrations up to $28 \mu \mathrm{mol} \mathrm{Cu} \mathrm{g}^{-1}$ and allow copper sulfide to form in situ after 20 days equilibration (named the AVS-Cu series).

The second approach differed in that AVS-containing sediment was first prepared by reacting the low-AVS sediment with sulfide to create a sediment with the desired AVS concentration (the FeS-Cu series). The $\mathrm{FeS}-\mathrm{Cu}$ sediments were also prepared in two stages, by first spiking dissolved $\mathrm{Na}_{2} \mathrm{~S}$ into sub-oxic sediments, which was allowed to react for five days to form $30 \mu \mathrm{mol} \mathrm{Fe} \mathrm{g}^{-1}$ (as quantified by AVS). The FeS-Cu concentration series was then prepared by reacting the $30 \mu \mathrm{mol} \mathrm{Fe}{ }^{-1}$ sediment with different amounts of $\mathrm{CuSO}_{4}$ dissolved in deoxygenated water to form copper sulfide in situ (six concentrations up to $20 \mu \mathrm{mol} \mathrm{Cu} \mathrm{g}^{-1}$ ). At the end of the equilibration period, the AVS and SEM concentrations were determined for each sediment to provide information on the stoichiometry of the copper: sulfide reaction. Previous studies showed that copper spiked into sulfidic sediments is reduced and forms $\mathrm{Cu}_{2} \mathrm{~S}$, rather than $\mathrm{CuS}$ (Simpson et al., 2000a).

The third approach involved spiking the low-AVS sediments with synthesised copper sulfide that had been prepared by reacting $\mathrm{CuSO}_{4} \cdot 5 \mathrm{H}_{2} \mathrm{O}$ (Univar, Ajax Finechem) dissolved in deoxygenated water with dissolved $\mathrm{Na}_{2} \mathrm{~S} \cdot 9 \mathrm{H}_{2} \mathrm{O}$ (Sigma) for $6 \mathrm{~h}$. The stoichiometry of the copper sulfide phases that formed was not determined, and may have been $\mathrm{CuS}, \mathrm{Cu}_{2} \mathrm{~S}$ or a mixture of the two. This series contained six concentrations up to $20 \mu \mathrm{mol} \mathrm{Cu} \mathrm{g}^{-1}$ was prepared by mixing with the low-AVS sediment, and was named the CuS series. The CuS series control was created by spiking the sediment with $20 \mu \mathrm{mol} \mathrm{g}^{-1} \mathrm{Na}_{2} \mathrm{~S}$. These sediments allowed comparison of the oxidation of copper sulfide in sub-oxic sediments (CuS series) with that of anoxic sediments (FeS-Cu series). In addition to these copper sulfide containing sediments, the low-AVS sediment was also spiked with dissolved copper using the methods described previously (Simpson et al., 2004; Hutchinson et al., 2007) (the Oxic-Cu series). 


\subsection{General toxicity test procedures}

Melita plumulosa is an epibenthic deposit-feeding amphipod commonly found in estuarine tidal mudflats ranging from silty to sandy sediments in freshwater, estuarine and marine environments throughout south-eastern Australia (Hyne et al., 2005). M. plumulosa, were obtained from laboratory cultures that were maintained as described previously (King et al., 2006). Juvenile M. plumulosa were harvested from 14-day old cultures of gravid females using a $210 \mu \mathrm{m}$ sieve and the largest juveniles ( $11 \pm 3$ days old, 0.5 to $1 \mathrm{~mm}$ body length) were selected for tests (Spadaro et al., 2008).

The 10-day water-only and whole-sediment toxicity tests with M. plumulosa were conducted in accordance with standard protocols (Spadaro et al., 2008; Strom et al., 2011). In brief, all toxicity tests were performed at $21 \pm$ $2^{\circ} \mathrm{C}$ in a constant environmental chamber (Labec Refrigerated Cycling Incubator) on a 12-h light/12-h dark cycle (light intensity $=3.5 \mu \mathrm{mol}$ photons s $\mathrm{s}^{-1} \mathrm{~m}^{-2}$ ) for the test duration. Glass beakers and acrylic beaker-lids used for toxicity tests were cleaned in a dishwasher (Gallay Scientific Pty Ltd) programmed for a phosphate-free detergent wash (Clean A, Gallay Scientific Pty), a dilute acid wash ( $1 \% \mathrm{HNO}_{3}$ ), followed by thorough rinsing with Milli-Q water. The physicochemical parameters of dissolved oxygen (>85\%), pH (7.5 to 8.2), salinity (30 \pm 1 PSU) and temperature $\left(21 \pm 2^{\circ} \mathrm{C}\right)$ were monitored and maintained throughout the test period according to Spadaro et al. (2008).

The water-only tests comprised four replicate $250 \mathrm{~mL}$ beakers containing $220 \mathrm{~mL}$ seawater and 20 juvenile M. plumulosa per treatment. Nominal copper concentrations were achieved by spiking seawater with $100 \mathrm{~g} \mathrm{~L}^{-1}$ of $\mathrm{CuSO}_{4} \cdot 5 \mathrm{H}_{2} \mathrm{O}$ and the beakers were conditioned with the test water for one day prior to test commencement. Food was added during water-only tests after each water change at a rate of $1 \mathrm{mg}$ fish powder per organism (Sera micron, Sera Fishtamins ${ }^{\circledR}$ ). The whole-sediment tests comprised four replicate containing 15 juvenile M. plumulosa per treatment, with the sediment and water volumes depending on test purpose (described below). As pervious tests had demonstrated that food was generally not required to achieve adequate survival in controls (Spadaro et al., 2008), no food was added during sediment tests except in those specified below.

The test water or overlying water in sediment tests was changed before adding the amphipods and exchanged with new test water on days 3,5 and 7 . Water subsamples were taken $(<0.45 \mathrm{~mm}$ filtered) for analyses at the start and finish of all tests, and before and after water renewals. The frequency of water changes required during the sediment bioassays was determined in preliminary tests run without organisms to ensure that dissolved copper concentrations were maintained below the 10-day water-only no observed effect concentration (NOEC) of $36 \mu \mathrm{g} \mathrm{L}^{-}$ ${ }^{1}$ for juvenile M. plumulosa (Spadaro et al., 2008; Strom et al., 2011). This involved measuring the dissolved copper to overlying waters for all sediments preparations over a $24-\mathrm{h}$ period under the same conditions used in toxicity tests, but without amphipods. The reported concentration of dissolved $\mathrm{Cu}$ in each treatment was the timeaveraged concentration (Angel et al., 2010).

Survival was determined at the completion of tests, and was indicated by active movement, confirmed under a dissection microscope. Sediment tests were terminated by gently sieving the sediment tests through a 180-mm stainless-steel sieve, and then the contents were transferred to large amphipod counting trays. Live amphipods were 
counted and removed, and the sieved sediment was then transferred into 120 -ml polycarbonate vials with approximately $100 \mathrm{~mL}$ of seawater, fixed with $4 \mathrm{~mL} \mathrm{10 \%} \mathrm{v/v} \mathrm{neutral} \mathrm{phosphate-buffered} \mathrm{formalin,} \mathrm{and} \mathrm{stained} \mathrm{with}$ $5 \mathrm{ml}$ Rose Bengal solution (0.1 g Rose Bengal salt/100 mL Milli-Q water). The sediment was then left for $72 \mathrm{~h}$ to enable any surviving amphipods, missed in the initial count, to take up the stain, and then these amphipods were counted. Tests were considered acceptable when the physicochemical parameters remained within acceptable limits throughout the test, and if survival of organisms was on average $>80 \%$ in the controls.

\subsection{Influence of AVS concentration, sulfide oxidation and added food on toxicity to M. plumulosa}

To demonstrate the effects of AVS on the toxicity of copper to M. plumulosa, a comparison was made between the toxicity of the Oxic-Cu (AVS $<1 \mu \mathrm{mol} / \mathrm{g}$ ) and the three AVS-Cu concentration series (AVS of 11, 18, $30 \mu \mathrm{mol} / \mathrm{g}$ ). These tests were conducted in 250-mL beakers containing $20 \mathrm{~g}$ of sediment (approximately $40 \mathrm{~mL}$ ) and $200 \mathrm{~mL}$ of seawater. The homogenized sediments were added $24 \mathrm{~h}$ before the test was started, and seawater was added slowly to minimize sediment resuspension. This created a sediment depth of $4-5$ mm, whereas the juvenile amphipods are epibenthic and were observed to burrow within the top 1-2 mm of the sediment.

The tests of the FeS-Cu and $\mathrm{CuS}$ concentration series were undertaken in 100-mL beakers containing $10 \mathrm{~g}$ (approximately $20 \mathrm{~mL}$ ) of test material and $90 \mathrm{~mL}$ seawater. The sulfide phases were added just an hour before the amphipods were added and tests started. Seawater was added slowly to minimize sediment resuspension. The materials formed a 1 to $2 \mathrm{~mm}$ layer and this resulted in there being no pore water. The survival of $M$. plumulosa in FeS-Cu and $\mathrm{CuS}$ controls (no copper) was $>80 \%$, indicating adequate nutrition. As there was negligible pore water in the FeS-Cu and $\mathrm{CuS}$ tests, and the dissolved copper concentrations in the overlying water were generally well below the 10-day NOEC of $36 \mu \mathrm{g} \mathrm{L}^{-1}$, any toxicity observed was likely to have a significant contribution from the dietary exposure route. To determine whether added food influenced the observed toxicity, the FeS-Cu and $\mathrm{CuS}$ series were tested both with and without feeding (1 mg fish powder per organism added after each water change).

For all of these experiments, the test waters were renewed on days 3,5 and 7 by replacing $80 \%$ of the overlying water with clean seawater. Sub-samples of overlying water were taken $(<0.45 \mu \mathrm{m}$ filtered $)$ for analyses at the start and finish of all tests, and before and after water renewals. Analyses of AVS and SEM-Cu were made at the start and finish of all tests to provide information on the oxidation of AVS and copper sulfide phases.

\subsection{Statistical analyses.}

Results of the toxicity tests were reported as percentage survival in test sediments relative to controls. Methods for statistical treatment of the data have been described previously (Spadaro et al., 2008). In brief, these data were arcsine transformed and tested for normality of distribution (Shapiro-Wilks test) and homogeneity of variance (Bartlett's test) prior to hypothesis testing. Dunnett's test (parametric) was then used if assumptions of normality and homogeneity of variances were met, while Steel's Many-One Rank test (non-parametric) was used when variances were heterogeneous or the distribution unequal. Maximum likelihood regression using probit analysis with Abbott's correction or non-linear interpolation with bootstrapping (Icp) (if assumptions of the probit analysis were not met) were also used to determine LC50, LC20, LC10 values and their 95\% confidence limits 
220 (CLs). Significance in all statistical tests was set at the $\mathrm{p}<0.05$ level and all statistical analyses were carried out

221 using the software package Toxcalc (version 2.3) for Microsoft Excel (TidePool Scientific Software, California, 222 USA).

\section{Results and discussion}

\subsection{Properties of copper sulfide spiked sediments.}

Copper sulfides are largely insoluble in $1 \mathrm{M} \mathrm{HCl}$ (Simpson et al., 1998; Cooper and Morse, 1998). Analyses of the synthesised copper sulfide (before addition to the sediments) found that $<0.5 \mu$ mol AVS g ${ }^{-1}$ was extractable in $1 \mathrm{M} \mathrm{HCl}$, whereas 1-h and 24-h extraction periods resulted in release of $11 \pm 3$ and $23 \pm 3 \%$ (mean $\pm \mathrm{SE}, \mathrm{n}=3$ ) of the total copper, respectively. In the AVS analyses, iron(III) phases in sediments have been shown to catalyse the dissolution of copper sulfide phases in $1 \mathrm{M} \mathrm{HCl}$, resulting in the liberation of copper and sulfur, rather than sulfide (Simpson et al., 1998; Simpson et al., 2000b). This is a key difference between the chemistry of copper sulfide to the other metals sulfides (e.g. FeS, MnS, ZnS, etc) and means that AVS and SEM analyses of sediments containing large portions of copper sulfide should also be interpreted differently. Firstly, increasing additions of copper should decrease the amount of AVS that is measureable in sediments, and this should be in proportion to the stoichiometry of the copper sulfide phases that form. Secondly, the varying solubilities in $1 \mathrm{M} \mathrm{HCl}$ of different iron (III) phases in sediments makes it difficult to predict the influence of iron on the extractability of copper from copper sulfide phases.

For the AVS-Cu and FeS-Cu series sediments, the copper sulfide was allowed to form in situ by reaction of copper with iron sulfide, FeS, which is the major AVS phase in most sediments. As AVS was liberated from the FeS phases, but not from copper sulfides phases, the changes in AVS measured were used to determine that the stoichiometry of the copper sulfide phases forming were $\mathrm{Cu}_{2} \mathrm{~S}$, rather than CuS (Table S1 and Figure $\mathrm{S} 1$ of the Supplementary Information). Overall, the observations were consistent with previous studies that have demonstrated that $\mathrm{Cu}_{2} \mathrm{~S}$ forms in preference to $\mathrm{CuS}$ in sediments and that both $\mathrm{CuS}$ and $\mathrm{Cu}_{2} \mathrm{~S}$ are largely insoluble in $1 \mathrm{M} \mathrm{HCl}$ (Casas and Crecelius, 1994; Simpson et al., 1998; Cooper and Morse, 1998; Simpson et al., 2000a).

The concentrations of AVS and SEM-Cu measured for the three copper sulfide series at the start and at completion of the toxicity tests are shown in Figure 1 (Tables S1 of the Supplementary Information). All of the 30 $\mu \mathrm{mol} \mathrm{g}{ }^{-1}$ AVS-Cu series sediments contained a molar excess of AVS over added copper (i.e. positive values for AVS - Added Cu in Table S1) and the measured SEM-Cu was initially just 1-2\% of the total copper (Figure 1d). The 18 and $11 \mu \mathrm{mol} \mathrm{g}{ }^{-1}$ AVS-Cu series sediments were prepared by mixing the highly sulfidic and oxic base materials, and the copper-spiked sediments contained either no excess or a small excess of AVS over added copper. The SEM-Cu measured (before tests) represented 18-23\% and 39-46\%, respectively, of the added copper. Consequently, while the AVS analyses indicated that $\mathrm{Cu}_{2} \mathrm{~S}$ phases had formed, the SEM-Cu results indicated that a significant portion of the sulfidised copper was extractable due the presence of oxidised iron phases.

For the FeS-Cu series, the initial SEM-Cu concentrations ranged from 20-48\% of total copper (Figures 1e, Table S1). While such high extractability of SEM-Cu was not expected due to the significant excess of AVS over 
added copper in all sediments, this is likely to have been due to the high amounts of non-sulfidised iron(III) present in the sediments. The sediments contained $140-180 \mu \mathrm{mol} \mathrm{g}^{-1} \mathrm{SEM}-\mathrm{Fe}$ and further Fe(III) phases may have formed by the oxidation of $\mathrm{Fe}$ (II) displaced from $\mathrm{FeS}$ during the reaction with added copper during the mixing and equilibration of the sediments (Simpson et al., 2000b; Hutchins et al., 2008). For the CuS series, 83-100\% of the total copper was measureable as SEM-Cu, indicating that either much of the added $\mathrm{CuS}$ had been oxidised during the mixing and equilibration period or the iron(III) phases present in these sediments were very effective at oxidising $\mathrm{CuS}$ phases during the $1 \mathrm{M} \mathrm{HCl}$ extractions. Although negligible dissolved oxygen would have been present in the sediments due to manipulation in a nitrogen atmosphere, sulfide is predicted to be thermodynamically unstable in the presence of oxidised iron and manganese phases (Simpson et al., 2000b; Millero, 2001) and the fine-sized synthetic copper sulfide may have been susceptible to oxidation through mixing (Hutchins et al., 2008). Overall, with increasing spiked-copper concentrations the percentage of SEM-Cu extracted decreased for the $\mathrm{CuS}$ series but increased for the FeS-Cu and three AVS-Cu series (Table S1). This is consistent with the lower extractability of SEM-Cu in sediments with greater degrees of sulfidisation and lower proportions of oxidised Fe phases (Simpson et al., 1998).

\subsection{Oxidation of copper sulfide phases and copper release to overlying water.}

The concentrations of AVS and SEM-Cu measured before and after the 10-day toxicity tests with the three copper-spiked sediment preparations are shown in Figure 1 (Tables S1 of the Supplementary Information). Within $24 \mathrm{~h}$ in all tests, a brownish layer of oxidised sediment of approximately $1 \mathrm{~mm}$ thickness had formed over the greyer sediments beneath. At the end of the AVS-Cu tests, the depth of the oxidised material had increased to 1-3 $\mathrm{mm}$ and the layering remained visible. In the $\mathrm{FeS}-\mathrm{Cu}$ tests, no layering was visible after $48 \mathrm{~h}$ indicating that the juvenile amphipods, with body lengths of $1 \pm 0.1 \mathrm{~mm}$ (Spadaro et al., 2008), were causing significant disturbance of the sediments.

Comparison of AVS concentrations measured for the AVS-Cu and FeS-Cu series sediments at the start and completion of the tests demonstrated that a significant percentage of AVS had oxidised during the 10-day test period (Figures 1a and b). For sediments that initially had $>1 \mu \mathrm{mol} \mathrm{AVS} \mathrm{g}^{-1}$, the AVS concentrations decreased by $32-67 \%, 76-97 \%$ and $82-97 \%$ in the 30, 18 and $11 \mu \mathrm{mol} \mathrm{g}^{-1}$ AVS-Cu series, and by 46-88\% for the FeS-Cu series. Signification oxidation of AVS was expected to be detected due to the thin layers of sediments used in these tests. Previously studies have also observed significant decreases in AVS concentrations during toxicity tests (Casas and Crecelius, 1994; Besser et al., 1996; DeLange et al., 2008). The oxidation of AVS was not able to be accurately assessed for the $\mathrm{CuS}$ series due to the low concentrations at the start of the tests (Figure 1c). The majority of whole-sediment toxicity test procedures utilise test sediment depths of $2 \mathrm{~cm}$ or less (Greenstein et al., 2008), and it is likely that oxidation of AVS in the surface sediments occurs during most test procedures. While the source of oxygen was expected to have been predominantly from the overlying water, we expect that the rate of oxidation will have been increased due to the burrowing activity of the amphipods (Peterson et a., 1996).

The degree of oxidation of the surface sediments was very evident from the changes in SEM-Cu. During the 10-day test period the copper extractable as SEM-Cu increased from 1-2\% to $70-90 \%, 18-23 \%$ to $52-71 \%$, and 
$39-46 \%$ to $72-92 \%$ for the 30,18 and $11 \mu$ mol g ${ }^{-1}$ AVS-Cu treatments, respectively (Figure 1d, Table S1). The rate of oxidation of $\mathrm{FeS}$ and $\mathrm{MnS}$ by oxygen is considerably more rapid than that of $\mathrm{CuS}$ or $\mathrm{Cu}_{2} \mathrm{~S}$ (Simpson et al., 1998; 2000) and the increased extractability of SEM-Cu at the end of the tests will be a result of increased amounts of iron hydroxide phases and also the direct oxidation of the copper sulfide phases. The FeS-Cu series sediments contained $\mathrm{Cu}_{2} \mathrm{~S}$ and $\mathrm{FeS}$, whereas the $\mathrm{CuS}$ series sediments contained $\mathrm{CuS}$ and mostly iron oxyhydroxide phases.

Owing to the differences in iron chemistry and the influence of iron on the extraction of SEM-Cu, it was not possible to determine from these experiments which of the $\mathrm{Cu}_{2} \mathrm{~S}$ or $\mathrm{CuS}$ phases oxidised more readily. It was also not possible to determine the relative contribution of dissolved oxygen or iron and manganese oxyhydroxides in the oxidation process. It was evident from the experiments that, over the 10-day period, the exposure to oxygenated overlying water and the foraging of amphipods resulted in considerable oxidation of copper sulfide phases in surface sediments, regardless of the form of the copper sulfide or iron chemistry.

For all of the copper-spiked sediment series, the porewater copper concentrations measured at the start of the tests were less than $10 \mu \mathrm{g} \mathrm{L}^{-1}$. For the AVS-Cu series, the sediment depth of 4-5 mm allowed for a small amount of porewater to exist, but the pore water was not reanalysed at the completion of the tests owing to the small amount of material. For the FeS-Cu and $\mathrm{CuS}$ series the tests were conducted on 1 to $2 \mathrm{~mm}$ layers that contained negligible porewater. Initial experiments found that, over a 24-h period, there was a significant release of dissolved copper to the overlying water from each of the test materials. This was consistent with oxidation of the copper sulfide phases, and was used to determine that renewing the overlying water every 2 to 3 days would prevent dissolved copper concentrations increasing above the 10-day NOEC of $36 \mu \mathrm{g} \mathrm{L}{ }^{-1}$ (Spadaro et al., 2008; Strom et al., 2011). In both the pore waters (before tests) and overlying waters during the tests, the concentrations of dissolved $\mathrm{Cd}$, $\mathrm{Ni}$ and $\mathrm{Pb}$ were $<3 \mu \mathrm{g} \mathrm{L}^{-1}$, and $\mathrm{Zn}$ was $<15 \mu \mathrm{g} \mathrm{L}{ }^{-1}$. Past studies have shown that copper is much more toxic than each of these metals and that no lethality would occur to juvenile M. plumulosa at these concentrations (King et al., 2006; Mann et al., 2010).

The time-averaged dissolved copper concentrations were determined from dissolved copper measurements on days 1, 5 and 10 of the tests (Figures $2 \mathrm{a}$ and b). In general, the mean dissolved copper concentrations increased linearly with increasing (spiked) sediment copper concentration. For the AVS-Cu series, the measured dissolved copper concentrations were greater in the sediments that had the lower AVS concentrations (Figure 2a), which is consistent with the greater binding of copper as copper sulfide phases in sediments with greater AVS concentrations. The concentrations of dissolved and particulate copper were strongly correlated $(r>0.9, p<0.01)$ and indicated that desorption of copper from the sediments was the principal source of the dissolved copper in the overlying water.

\subsection{Copper toxicity and exposure pathways}

From the 10-day water-only tests, LC50 (95\% confidence limits), LC20 and LC10 values of 87 (70-104), 53 and $41 \mu \mathrm{g} / \mathrm{L}$, respectively, were determined for juvenile M. plumulosa. Previous studies had reported LC50 and NOEC values of $76 \pm 15 \mu \mathrm{g} / \mathrm{L}$ and $36 \mu \mathrm{g} \mathrm{L}^{-1}$ (Spadaro et al., 2008). The survival in the control sediments for each 
added copper. The sediments comprised $>95 \%$ silt and $4 \%$ TOC and, consistent with past studies (Spadaro et al., 2008), the adequate survival in the controls indicated that sediment nutrition was not significantly influencing the results. In each copper sulfide series, the sediments became toxic to M. plumulosa at the higher copper concentrations (Figures $2 \mathrm{c}$ and d). At the same total copper concentrations, the FeS-Cu series sediments caused greater toxicity than the $\mathrm{CuS}$ series (Figure 2d), despite the very similar dissolved copper concentrations in the overlying water (Figures $2 \mathrm{~b}$ ). Toxicity was observed for each series even though the mean dissolved copper concentrations in the overlying waters were generally below the NOEC value of $36 \mu \mathrm{g} \mathrm{L}^{-1}$ (Figures $2 \mathrm{a}$ and $\mathrm{b}$ ).

M. plumulosa reside at the sediment-water interface (SWI) and the dissolved copper exposure will occur via copper in the porewater or overlying water. Recent studies have shown that the flux of copper may be significantly greater in the few mm below the SWI compared to both the deeper pore water and the overlying water (TankereMuller et al., 2006). The use of thin layers of sediments meant that negligible pore water existed in the FeS-Cu and $\mathrm{CuS}$ experiments, and the dissolved copper released at the SWI was expected to be rapidly diluted due to the continual mixing of the overlying waters created by the gas bubbling. In past studies of copper with juvenile $M$. plumulosa, Strom et al. (2011) calculated LC15 and LC50 values of 36 and $68 \mu \mathrm{g} / \mathrm{L}$ in overlying water of tests using copper-spiked sediments, by extrapolation to exposure conditions containing no particulate copper. The closeness of those values to the values determined in the present study indicates that the dissolved copper concentrations at the SWI and in the overlying waters were similar in the sediment bioassays. Based on the results of the present study and the earlier studies, we do not believe that dissolved copper in the pore water, SWI or overlying water were the only copper contributions to the observed toxicity (Figure 2).

Previous studies have demonstrated that M. plumulosa ingest sediments while foraging for food (King et al., 2005; Simpson and King, 2005), and this may contribute to the observed toxicity (Simpson, 2005; Strom et al., 2011). In the present study, adequate survival was observed in the controls with and without added food but survival in the $\mathrm{FeS}-\mathrm{Cu}$ and $\mathrm{CuS}$ series increased when additional food (dried, powdered fish) was added (Figure 2d). Unexpectedly, the dissolved copper concentrations were significantly greater (often double) in the tests with no added food (Figure $2 \mathrm{~b}$ ) indicating that the higher dissolved copper concentrations were not increasing the toxicity. Copper forms strong complexes with organic ligands present in sediment porewaters and overlying water (Vink, 2009). It is possible that the added food also provided an additional source of copper complexing ligands that increased the rate of release of copper from particles but decreased the bioavailability of copper in the dissolved phase. This was discounted as the sole reason for the decrease in toxicity as the $10 \mathrm{~g}$ of sediment (containing 4\% TOC) was expected to contain a greater source of copper-complexing ligands than the $15 \mathrm{mg}$ of fish food was added at each water change ( $45 \mathrm{mg}$ in total per test).

The increase in amphipod survival in the $\mathrm{CuS}$ and $\mathrm{FeS}-\mathrm{Cu}$ series with food added was attributed to a combination of factors, including increased robustness of the organisms, greater complexation of dissolved copper in the overlying water, and ingestion of less of the copper-contaminated sediment. The observations add to the growing body of evidence of toxic effects through diet for this amphipod species (Simpson and King, 2005; King et al., 2006; Spadaro et al., 2008; Mann et al., 2009; Strom et al., 2011). While the added food will have adsorbed 
some of the released copper and would act as an avenue of metal exposure, this will not have been a significant source of copper to the amphipods.

Because some copper sulfide phases were oxidised during the tests (Figure 1), it was not possible to distinguish between the possible effects of ingesting sulfide and non-sulfide forms of particulate copper. Previous studies have demonstrated that benthic bivalves and polychaetes can accumulate metals from sediments that have a molar excess of AVS compared to SEM (Lee et al., 2000; Otero et al., 2000; Griscom and Fisher, 2004; De Jonge et al., 2009 and 2010). It is possible that the metal accumulation observed in those studies may have also occurred following the partial oxidation of metal sulfide phases in the sediments, or through the existence microenvironments that contained oxidised forms of the metals within the anoxic sediments.

\subsection{AVS-SEM model predictions and copper effects thresholds}

For sediments that contain an excess of AVS over SEM concentrations, the porewater concentrations of Cd, $\mathrm{Cu}, \mathrm{Ni}, \mathrm{Pb}$ and $\mathrm{Zn}$ are predicted to be negligible and acute or chronic effects should not result from these metals (USEPA, 2005). This forms the basis of the AVS-SEM model for predicting toxicity of these metals in sediments (Di Toro et al., 2005). For all treatments, the SEM-Cd, Ni, Pb and $\mathrm{Zn}$ concentrations were 0.002, 0.044, 0.15 and $2.1 \mu \mathrm{mol} \mathrm{g}{ }^{-1}$, respectively. This $2.3 \mu \mathrm{mol} \mathrm{g}{ }^{-1}$ of non-copper SEM was a minor contribution to the total SEM (Figure 1, Table S1). For the three AVS-Cu series, the toxicity was less in the sediments that had the greater AVS concentrations (Figure 2c), which is consistent with AVS reducing the bioavailability of copper.

Due to oxidation of AVS, sediments that had a molar excess of AVS compared to SEM-Cu at the start of the tests, did not always have an excess at the end of the tests (Figure 1). Casas and Crecelius (1994) and Besser et al. (1996) have previously observed the oxidation of copper and zinc sulfide phases during toxicity tests of both marine and freshwater sediments, respectively. When the initially measured AVS and SEM concentrations were used, the AVS-SEM model did not provide useful predictions of metal toxicity (Figure 3a). However, when the AVS and SEM concentrations measured at the end of the tests were used the AVS-SEM model provides a suitable prediction of the transition from non-toxic to potentially toxic metal concentrations (Figure 3b).

For two of the FeS-Cu series, toxicity was observed in the sediments having a small molar excess of AVS over SEM-Cu at the completion of the tests. While this is considered to be within the experiment error of the SEM - AVS analyses, it is also possible that the small amount of AVS that was present after 10 days was present inside the particles and having little influence on the bioavailability of metals adsorbed to the oxidised outer layer. At the same total copper concentrations, the FeS-Cu series sediments cause greater toxicity than the CuS series (Figure 2d), despite the $\mathrm{CuS}$ series having much higher SEM-Cu concentrations and similar dissolved copper concentrations in the overlying water (Figure 2b). At the start of the tests, the FeS-Cu series had 20 to $30 \mu \mathrm{mol}$ $\mathrm{AVS} \mathrm{g}^{-1}$, while the CuS series has $0.7 \mu \mathrm{mol} \mathrm{AVS} \mathrm{g}{ }^{-1}$. While the oxidation of excess AVS in the FeS-Cu series (comprising mostly FeS) may have occurred quite rapidly in the surface layers, the CuS series was expected to have a greater density of oxidised iron and manganese oxyhydroxide phases to which copper released during oxidation of $\mathrm{CuS}$ could rapidly bind. 
Overall, the results are consistent with past studies that have demonstrated that AVS reduces the bioavailability of copper in sediments (Ankley et al., 1993; Berry et al., 1996) and the predictions of the AVS-SEM model (Di Toro et al., 2005; USEPA, 2005; Simpson et al., 2011). Effects thresholds (LC50, LC20, and LC10) based on total particulate copper concentrations were calculated for the AVS-Cu, FeS-Cu and CuS series sediments (Table 1). Recently, Simpson et al. (2011) used acute effects data for 12 benthic organisms to calculate an acute no effects threshold of $510 \mathrm{mg} \mathrm{kg}^{-1}$ for copper-spiked oxic silty sediments from the same origin as those used in this study. In that study, the LC50, LC20 and LC10 values for juvenile M. plumulosa in sediments equivalent to the $\mathrm{Cu}$-oxic series were 940, 790, and $720 \mathrm{mg} \mathrm{kg}^{-1}$ (no added food), approximately $200 \mathrm{mg} \mathrm{kg}^{-1}$ higher than the value determined in the present study $\left(730,570\right.$, and $490 \mathrm{mg} \mathrm{kg}^{-1}$, Table 1$)$. While those differences may be attributed to variations in the sensitivity of different batches of juveniles, the much lower $\mathrm{LCx}$ values of the $\mathrm{FeS}-\mathrm{Cu}$ and $\mathrm{CuS}$ series (140-690 $\mathrm{mg} \mathrm{kg}^{-1}$ ) indicate that differences in test design (e.g. depth of test material) and the copper exposure were contributing to the greater toxicity of the $\mathrm{FeS}-\mathrm{Cu}$ and $\mathrm{CuS}$ series.

The presences study highlights the importance of considering the temporal nature of AVS in sediments and the need to monitor the presence of this phase and its influence on the bioavailability of metals in surface sediments. The existence of an excess of AVS over SEM in a bulk sediment may not necessary mean that the microenvironment in which an organism lives, e.g. the burrows or surface sediments, contains the similar level of metal binding by sulfide. As most whole-sediment toxicity test procedures utilise shallow sediment depths (Greenstein et al., 2008), oxidation of significant amounts of AVS will occur during most test procedures (Ankley et al., 1993; Peterson et a., 1996; Eriksson-Wiklund and Sundelin, 2002; De Lange et al., 2008).

While copper sulfide phases are relatively slow to oxidise, and released copper is readily adsorbed by a range of other sediment phases, other AVS-bound metals may become much more bioavailable within oxidised surface sediments. It is now well recognised that along with AVS, the bioavailability of metals in sediments is also strongly influenced by POC and iron and manganese oxyhydroxide phases associated with silt (Besser et al., 2003; Di Toro et al., 2005; Simpson and Batley, 2007; De Jonge et al., 2009; Strom et al., 2011). The absence of toxicity in the AVS-Cu and CuS series until a $10 \mu \mathrm{mol} \mathrm{g}{ }^{-1}$ excess of SEM-Cu over AVS (greater than $600 \mathrm{mg} \mathrm{Cu} / \mathrm{kg}$ ) is consistent with the presence of these copper-binding phases (Figure 4b). While methods for incorporating both dissolved and dietary exposure routes into mechanistic based guidelines still requires further development (Simpson, 2005), the use of guidelines that vary with changes in AVS, POC, and silty contents provide significant improvement over single values guidelines that are frequently applied to all sediment types (Di Toro et al., 2005; Strom et al., 2011; Simpson et al., 2011).

\section{Acknowledgements}

We thank Graeme Batley and David Spadaro for their constructive comments on the manuscript. This work was, in part, funded by the BHP Billiton, Rio Tinto and Xstrata through a PhD grant for D Strom. 
Chemical properties, including AVS and SEM-Cu concentrations measured before and after toxicity tests, of the copper sulfide spiked sediments. This material is available free of charge via the Internet at http://pubs.acs.org.

\section{References}

Angel, B.M., Simpson, S.L., Jolley, D.F., 2010. Toxicity to Melita plumulosa from intermittent and continuous exposures to dissolved copper. Environ. Toxicol. Chem. 29, 2823-2830.

Ankley, G.T., Mattson, V.R., Leonard, E.N., West, C.W., Bennett, J.L., 1993. Predicting the acute toxicity of copper in freshwater sediments: evaluation of the role of acid-volatile sulfide. Environ. Toxicol. Chem. 12, 315-320.

Berry, W.J., Hansen, D.J., Mahony, J.D., Robson, D.L., Di Toro, D.M., Shipley, B.P., Rogers, B., Corbin, J.M.,Boothman, W.S., 1996. Predicting the toxicity of metal-spiked laboratory sediments using acid-volatile sulfide and interstitial water normalizations. Environ. Toxicol. Chem. 15, 2067-2079.

Besser, J.M., Ingersoll, C.G., Giesy, J.P., 1996. Effects of spatial and temporal variation of acid-volatile sulfide on the bioavailability of copper and zinc in freshwater sediments. Environ. Toxicol. Chem. 15, 286-293.

Besser, J.M., Brumbaugh, W.G., May, T.W., Ingersoll, C.G., 2003. Effects of organic amendments on the toxicity and bioavailability of cadmium and copper in spiked formulated sediments. Environ. Toxicol. Chem. 22, 805-815.

Caetano, M., Madureira, M.-J., Vale, C., 2003. Metal remobilisation during resuspension of anoxic contaminated sediment: short-term laboratory study. Water Air Soil Pollut. 143, 23-40.

Casado-Martinez, M.C., Smith, B.D., Luoma, S.N., Rainbow, P.S., 2010. Metal toxicity in a sediment-dwelling polychaete: Threshold body concentrations or overwhelming accumulation rates? Environ. Pollut. 158, 3071-3076.

Casas, A.M., Crecelius, E.A., 1994. Relationship between acid volatile sulfide and the toxicity of zinc, lead and copper in marine sediments. Environ. Toxicol. Chem. 13, 529-536.

Chapman, P.M., Wang, F., Janssen, C., Persoone, G., Allen, H.E., 1998. Ecotoxicology of metals in aquatic sediments: binding and release, bioavailability, risk assessment, and remediation. Can. J. Fish. Aquat. Sci. 55, 2221-2243.

Cooper, D.C., Morse, J.W., 1998. Extractability of metal sulfide minerals in acidic solutions - application to environmental studies of trace metal contamination within anoxic sediments. Environ. Sci. Technol. 32, 1076-1078.

De Lange, H.J., Van Griethuysen, C., Koelmans, A.A., 2008. sampling method, storage and pretreatment of sediment affect AVS concentrations with consequences for bioassay responses. Environ. Pollut., 151, 243-251.

De Jonge, M., Dreesen, F., De Paepe, J., Blust, R., Bervoets, L., 2009. Do acid volatile sulfides (AVS) influence the accumulation of sediment-bound metals to benthic invertebrates under natural field conditions? Environ. Sci. Technol. 43, $4510-4516$.

De Jonge, M., Blust, R., Bervoets, L. 2010. The relation between acid volatile sulfides (AVS) and metal accumulation in aquatic invertebrates: implications of feeding behavior and ecology. Environ. Pollut., 158, 1381-1391.

Di Toro, D.M., McGrath, J.A., Hansen, D.J., Berry, W.J., Paquin, P.R., Mathew, R., Wu, K.B., Santore, R.C., 2005. Predicting sediment metal toxicity using a sediment biotic ligand model: methodology and initial application. Environ. Toxicol. Chem. $24,2410-2427$.

Eggleton, J., Thomas, K.V., 2004. A review of factors affecting the release and bioavailability of contaminants during sediment disturbance events. Environ. Int. 30, 937-980.

Eriksson Wiklund, A.-K., Sundelin, B., 2002. Bioavailability of metals to the amphipod Monoporeia affinis: Interactions with authigenic sulfides in urban brackish-water and freshwater sediments. Environ. Toxicol. Chem. 21, 1219-1228.

Forster, S., 1996. Spatial and temporal distribution of oxidation events occurring below the sediment-water interface. Mar. Ecol. 17, 309-319.

Gallon, C., Hare, L., Tessier, A., 2008. Surviving in anoxic surroundings: how burrowing aquatic insects create an oxic microhabitat. J. North Am. Benthol. Soc. 27, 570-580.

Goulet, R.R., Krack, S., Doyle, P.J., Hare, L., Vigneault, B., McGeer, J.C., 2007. Dynamic multipathway modeling of Cd bioaccumulation in Daphnia Magna using waterborne and dietborne exposures. Aquat. Toxicol. 81, 117-125. 
Greenstein, D., Bay, S., Anderson, B., Chandler, G., Farrar, J., Keppler, C., Phillips, B., Ringwood, A., Young, D. 2008. Comparison of methods for evaluating acute and chronic toxicity in marine sediments. Environ. Toxicol. Chem. 27, 933-944.

Griscom, S.B., Fisher, N.S., 2004. Bioavailability of sediment-bound metals to marine bivalve molluscs: an overview. Estuaries 27, 826-838. Hutchins, C., Teasdale, P.R, Lee, S.Y., Simpson, S.L., 2008. Cu and Zn concentration gradients created by dilution of pH neutral metal-spiked sediment: Comparing the geochemical response with alternate methods of metal addition. Environ. Sci. Technol. 42, 2912-2918.

Hyne, R.V., Gale, S.A., King, C.K., 2005. Laboratory culture and life cycle experiments with the benthic amphipod Melita plumulosa (Zeidler). Environ. Toxicol. Chem. 24, 2065-2073.

Jorgensen, B.B., Revsbech, N.P., 1985. Diffusive boundary layers and the oxygen uptake of sediments and detritus. Limnol. Oceanogr. 30, 111-122.

King, C.K., Gale, S.A., Stauber, J.L., 2006. Acute toxicity and bioaccumulation of aqueous and sediment-bound metals in the estuarine amphipod Melita plumulosa. Environ. Toxicol. 21, 489-504.

King, C.K., Simpson, S.L., Smith, S.V., Stauber, J.L., Batley, G.E., 2005. Short-term accumulation of cd and cu from water, sediment and algae by the amphipod Melita plumulosa and the bivalve Tellina deltoidalis. Mar. Ecol.-Prog. Ser. 287, 177-188.

Kristensen E., 2000. Organic matter diagenesis at the oxic/anoxic interface in coastal marine sediments, with emphasis on the role of burrowing animals. Hydrobiologia 426, 1-24.

Lee, B.-G., Lee, J.-S., Luoma, S.N., Choi, H.J., Koh, C.-H., 2000. Influence of acid volatile sulfide and metal concentrations on metal bioavailability to marine invertebrates in contaminated sediments. Environ. Sci. Technol. 34, 4517-4523.

Mann, R.M., Hyne, R.V., Spadaro, D.A., Simpson, S.L., 2009. Development and application of a rapid amphipod reproduction test for sediment-quality assessment. Environ. Toxicol. Chem. 28, 1244-1254.

Millero, F.J., 2001. Physical Chemistry of Natural Waters. Wiley-Interscience: New York, NY.

Motelica-Heino, M., Naylor, C., Zhang, H., Davison, W., 2003. Simultaneous release of metals and sulfide in lacustrine sediment. Environ. Sci. Technol. 37, 4374-4381

Naylor, C., Davison, W., Motelica-Heino, M., van den Berg, G.A., van der Heijdt, L.M., 2006. Potential kinetic availability of metals in sulphidic freshwater sediments. Sci. Tot. Environ.357, 208-20.

Otero, X.L., Sanchez, J. M., Macias, F. 2000. Bioaccumulation of heavy metals in thionic fluvisols by a marine polychaete: The role of metal sulfides. J. Environ. Qual. 29, 1133-1141.

Peterson, G.S., Ankley, G.T., Leonard, E.N., 1996. Effect of bioturbation on metal-sulfide oxidation in surficial Freshwater sediments. Environ. Toxicol. Chem. 15, 2147-2155.

Simpson, S.L., 2001. A rapid screening method for acid volatile sulfide in sediments. Environ. Toxicol. Chem. 20 , $2657-2661$.

Simpson, S.L., 2005. An exposure-effect model for calculating copper effect concentrations in sediments with varying copper binding properties: a synthesis. Environ. Sci. Technol. 39, 7089-7096.

Simpson, S.L., Batley, G.E., 2003. Disturbances to metal partitioning during toxicity testing Fe(II)-rich estuarine pore waters and whole-sediments. Environ. Toxicol. Chem. 22, 424-432.

Simpson, S.L., Batley, G.E., 2007. Predicting metal toxicity in sediments: A critique of current approaches. Integ. Environ. Assess. Manag. 3, 3-16.

Simpson, S.L., King, C.K., 2005. Exposure-pathway models explain causality in whole-sediment toxicity tests. Environ. Sci. Technol. 39, 837-843.

Simpson, S.L., Spadaro, D.A., 2011. Performance and sensitivity of rapid sublethal sediment toxicity tests with the amphipod Melita plumulosa and copepod Nitocra spinipes. Environ. Toxicol. Chem. 30, DOI: 10.1002/etc.633.

Simpson, S.L., Angel, B.M., Jolley, D.F., 2004. Metal equilibration in laboratory-contaminated (spiked) sediments used for the development whole-sediment toxicity tests. Chemosphere 54, 597-609.

Simpson, S.L., Apte, S.C., Batley, G.E., 1998. Effect of short term resuspension events of trace metals speciation in polluted anoxic sediments. Environ. Sci. Technol. 32, 620-625.

Simpson, S.L., Apte, S.C., Batley, G.E., 2000b. Effect of short term resuspension events on the oxidation of cadmium, lead and zinc sulfide phases in anoxic sediments. Environ. Sci. Technol. 34, 4533-4537. 
Simpson, S.L., Micevska, T., Adams, M.S., Stone, A., Maher, W., 2007. Establishing cause-effect relationships in PAH and hydrocarbon contaminated sediments using the benthic marine alga, Entomoneis cf punctulata. Environ. Toxicol. Chem. 26, 163-170.

527 Simpson, S.L., Rosner, J., Ellis, J., 2000a. The competitive displacement reactions of Cd, Cu and $\mathrm{Zn}$ added to a polluted, 528 sulfidic estuarine sediment. Environ. Toxicol. Chem. 19, 1992-1999.

529 Simpson, S.L., Batley, G.E., Hamilton, I and Spadaro, D.A. 2011. Guidelines for copper in sediments with varying properties. 530 Chemosphere, doi:10.1016/j.chemosphere.2011.08.044.

531 Spadaro, D.A., Micevska, T., Simpson, S.L., 2008. Effect of nutrition on toxicity of contaminants to the epibenthic amphipod, 532 Melita plumulosa. Arch. Environ. Contam. Toxicol. 55, 593-602.

533 Strom D., Simpson, S.L., Batley, G.E., Jolley, D.F., 2011. Accounting for the influence of sediment particle size and organic 534 carbon on toxicity of copper to benthic invertebrates in oxic/sub-oxic surface sediments. Environ. Toxicol. Chem. 30, 15995351610.

536 Tankere-Muller, S., Zhang, H., Davison, W., Finke, N., Larsen, O., Stahl, H., Glud, R.N., 2006. Fine scale remobilisation of $537 \mathrm{Fe}, \mathrm{Mn}, \mathrm{Co}, \mathrm{Ni}, \mathrm{Cu}$ and $\mathrm{Cd}$ in contaminated marine sediment. Mar. Chem. 106, 192-120. USEPA, 2005. Procedures for the derivation of equilibrium partitioning sediment benchmarks (ESBs) for the protection of benthic organisms: Metal mixtures (cadmium, copper, lead, nickel, silver and zinc). U.S. Environmental Protection Agency, Office of Research and Development Report EPA-600-R-02-011, Washington, DC, USA.

541 Vink, J.P.M., 2009. The Origin of Speciation: Trace Metal Kinetics Over Natural Water/Sediment Interfaces and the 542 Consequences for Bioaccumulation. Environ. Pollut. 157, 519-527.

543 Wang, Z.S., Kong, H.N., Wu, D.Y., 2007. Reproductive toxicity of dietary copper to a saltwater cladoceran, Moina 544 Monogolica Daday. Environ. Toxicol. Chem. 26, 126-131. 


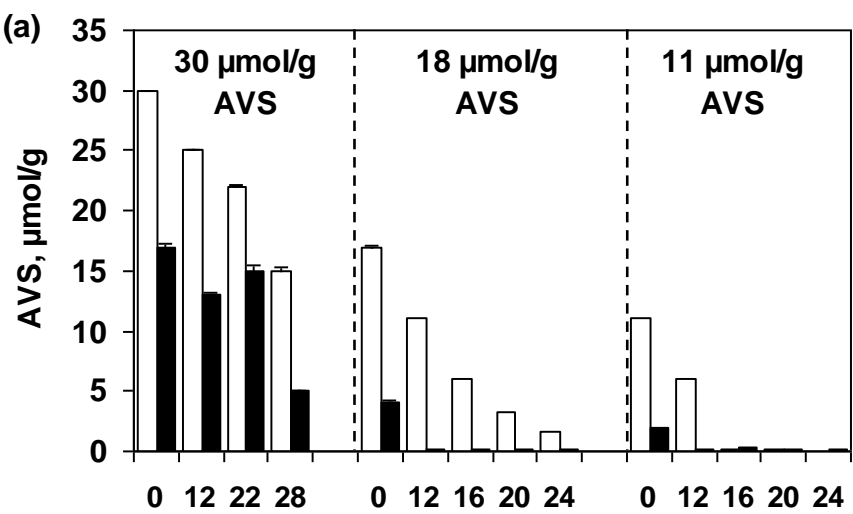

Copper added as AVS-Cu, $\mu \mathrm{mol} / \mathrm{g}$
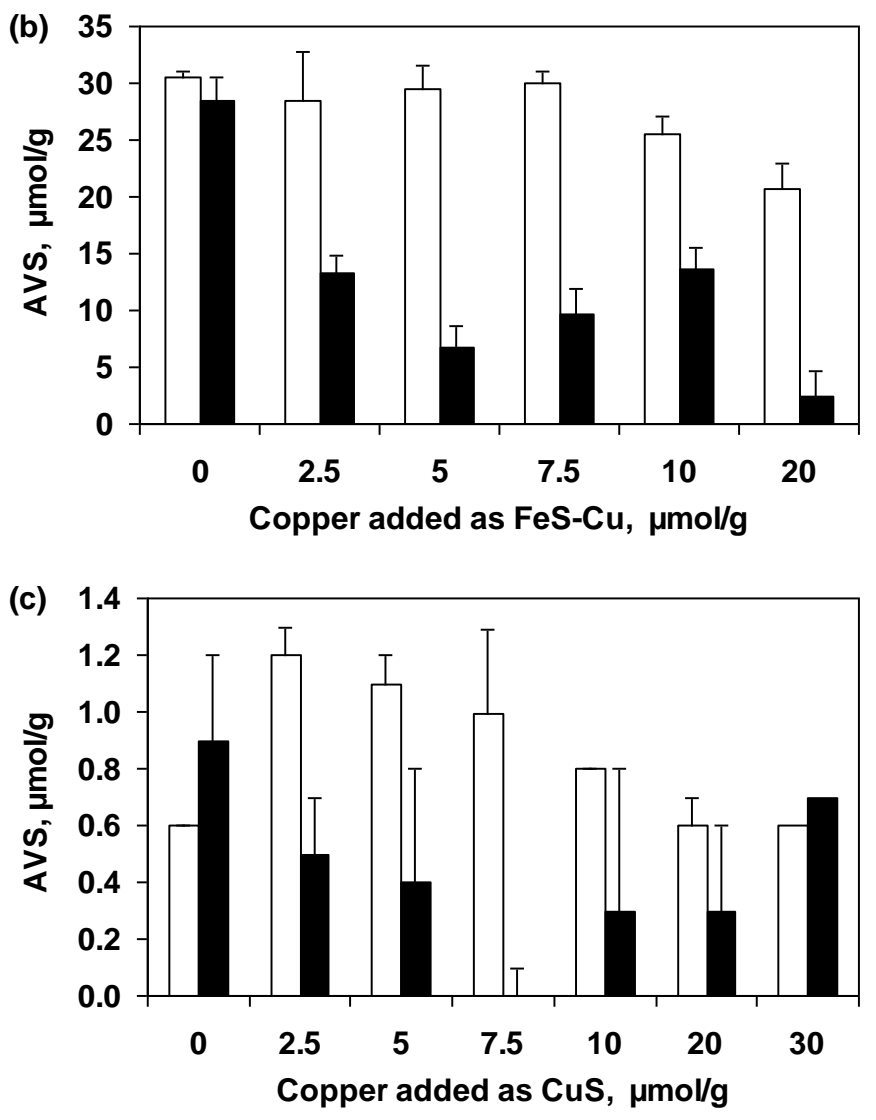

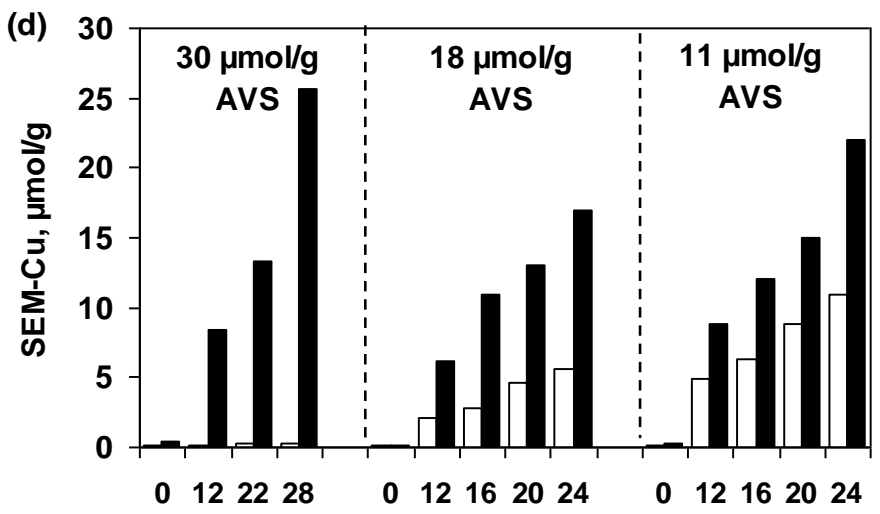

Copper added as AVS-Cu, $\mu \mathrm{mol} / \mathrm{g}$
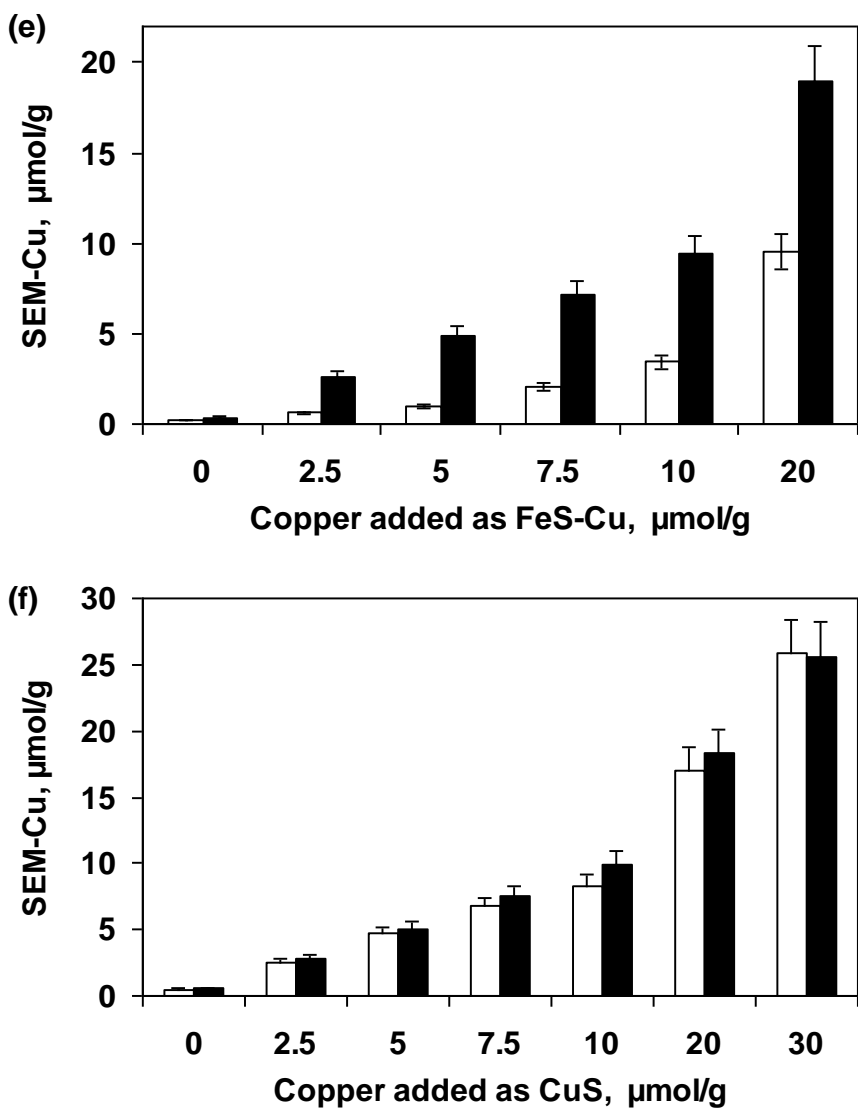

Fig. 1. AVS and SEM-Cu concentrations (mean $\pm 1 \mathrm{SD}, \mathrm{n}=3$ ) before $(\boldsymbol{\square})$ and after $(\square)$ 10-day toxicity tests for the copper sulfide spiked sediments: (a, b) AVS-Cu series; (c, d) FeS-Cu series, and (e, f) CuS series. 

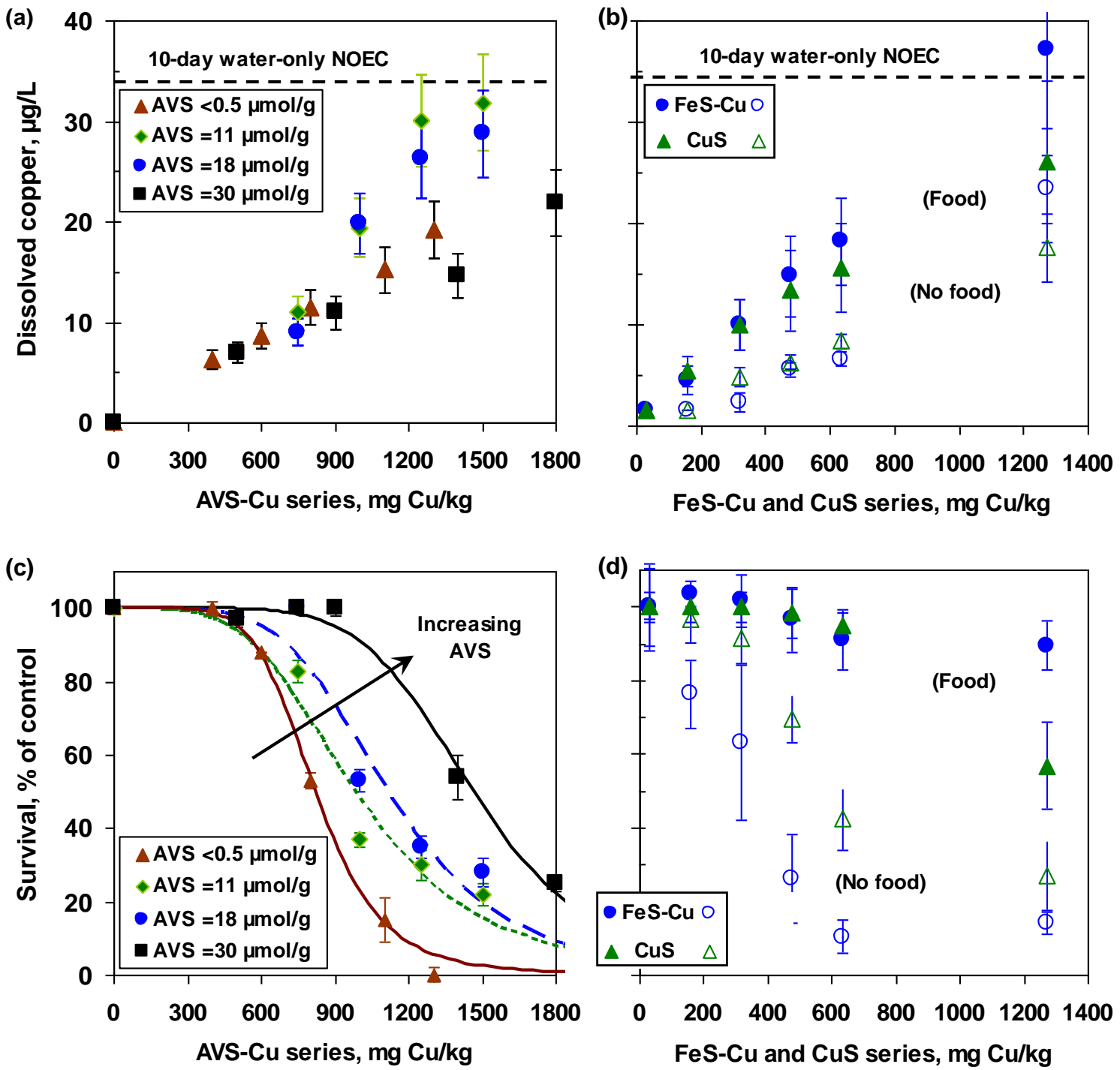

29 Fig. 2. Dissolved copper concentrations $(\mu \mathrm{g} / \mathrm{L})$ in the overlying water and 10-day survival of juvenile $M$.

30 plumulosa in 10-day whole-sediment toxicity tests of copper sulfide spiked sediments: (a, c) AVS-Cu series; (b, d)

31 FeS-Cu series and $\mathrm{CuS}$ series with (filled symbols) and without food added (open symbols. The data are means

32 with error bars representing standard error for three replicates. 
(a)

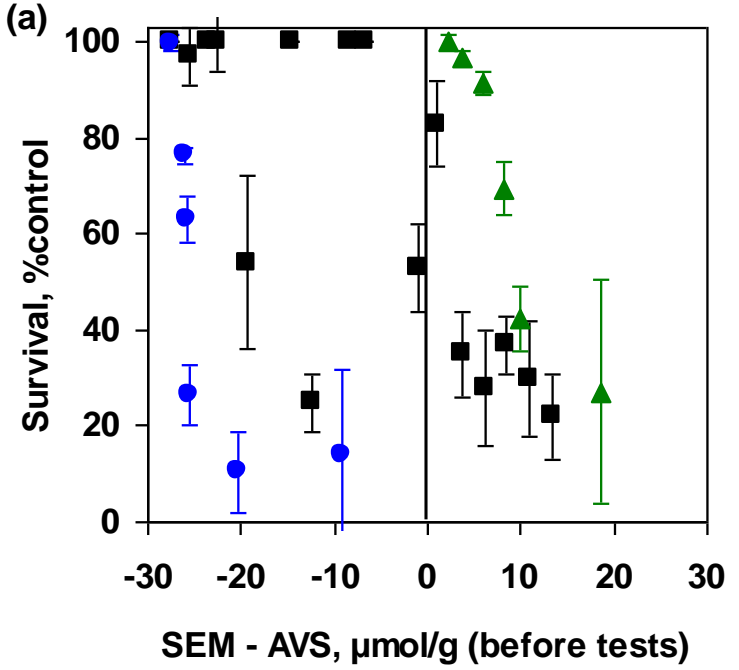

(b)

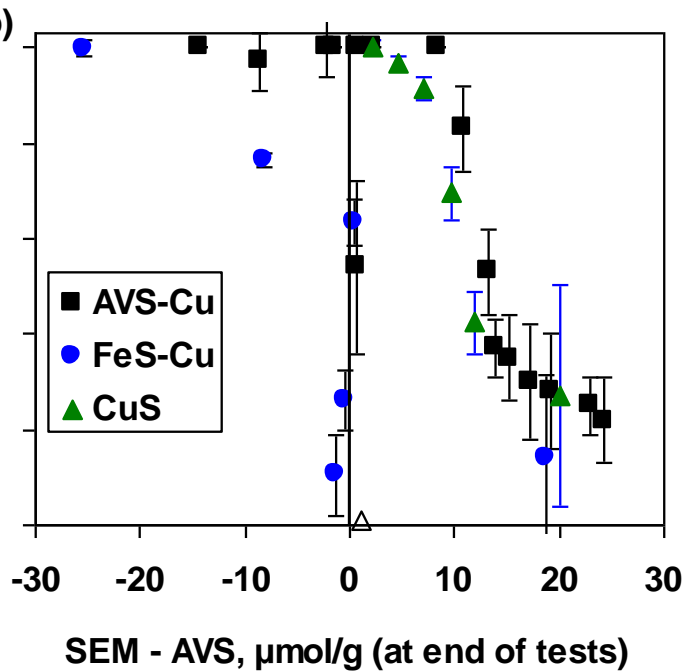

43 Fig. 3. Survival of juvenile $M$. plumulosa in relation to SEM - AVS models using measurements from the start and 44 end of 10-day tests. The data are means with error bars representing standard error for three replicates. 


\section{Tables}

9

10

11

12

\section{Table 1}

14 Effects concentrations for juvenile M. plumulosa exposure to copper-spiked sediments

\begin{tabular}{lccc}
\hline \multirow{2}{*}{$\begin{array}{l}\text { Copper spiked } \\
\text { sediment }\end{array}$} & \multicolumn{3}{c}{ Particulate copper, mg kg-1 } \\
\cline { 2 - 4 } & LC50 (95\% CL) & LC20 (95\% CL) & LC10 (95\% CL) \\
\hline Oxic/sub-oxic Cu & $730(690-770)$ & $570(530-620)$ & $490(440-550)$ \\
\hline AVS_11-Cu & $970(900-1050)$ & $690(600-780)$ & $560(600-780)$ \\
AVS_18-Cu & $1100(1030-1180)$ & $810(730-910)$ & $680(590-790)$ \\
AVS_30-Cu & $1460(1420-1500)$ & $1150(1090-1210)$ & $1000(930-1100)$ \\
\hline CuS-oxic (no food) & $690(580-810)$ & $330(260-430)$ & $220(150-310)$ \\
CuS-oxic (food) & $1800(1500-2000)$ & $850(670-1100)$ & $560(390-790)$ \\
\hline FeS-Cu (no food) & $320(220-400)$ & $190(92-410)$ & $140(50-390)$ \\
FeS-Cu (food) & \multicolumn{3}{c}{ No toxicity up to 1200 mg Cu kg-1 } \\
\hline \multicolumn{4}{l}{}
\end{tabular}

15

16

17

18

19

20

21

22

23

24

25

26

28

29

30

31 